\title{
Modelling Small-Scale Drifting Snow with a Lagrangian Stochastic Model Based on Large-Eddy Simulations
}

\author{
C. D. Groot Zwaaftink - M. Diebold · S. Horender • \\ J. Overney • G. Lieberherr • M. B. Parlange • \\ M. Lehning
}

Received: 3 July 2013 / Accepted: 6 May 2014 / Published online: 25 May 2014

C) Springer Science+Business Media Dordrecht 2014

\begin{abstract}
Observations of drifting snow on small scales have shown that, in spite of nearly steady winds, the snow mass flux can strongly fluctuate in time and space. Most drifting snow models, however, are not able to describe drifting snow accurately over short time periods or on small spatial scales as they rely on mean flow fields and assume equilibrium saltation. In an attempt to gain understanding of the temporal and spatial variability of drifting snow on small scales, we propose to use a model combination of flow fields from large-eddy simulations (LES) and a Lagrangian stochastic model to calculate snow particle trajectories and so infer snow mass fluxes. Model results show that, if particle aerodynamic entrainment is driven by the shear stress retrieved from the LES, we can obtain a snow mass flux varying in space and time. The obtained fluctuating snow mass flux is qualitatively compared to field and wind-tunnel measurements. The comparison shows that the model results capture the intermittent behaviour of observed drifting snow mass flux yet differences between modelled turbulent structures and those likely to be found in the field complicate quantitative comparisons. Results of a model experiment show that the surface shear-stress distribution and its influence on aerodynamic entrainment appear to be key factors in explaining the intermittency of drifting snow.
\end{abstract}

Keywords Drifting snow · Lagrangian stochastic model · Large-eddy simulations · Particle tracking $\cdot$ Saltation $\cdot$ Surface shear stress

C. D. Groot Zwaaftink $(\varangle) \cdot$ S. Horender · M. Lehning

WSL Institute for Snow and Avalanche Research SLF, Davos, Switzerland

e-mail: groot@slf.ch

C. D. Groot Zwaaftink · M. Diebold · J. Overney · G. Lieberherr · M. B. Parlange · M. Lehning

School of Architecture, Civil and Environmental Engineering, EPFL, Lausanne, Switzerland

S. Horender

Leibniz Institute for Tropospheric Research (TROPOS), Leipzig, Germany 


\section{Introduction}

Snow transport and its effect on the snow cover have been studied because of their impact on hydrology, avalanches and ecology. Furthermore, the understanding of the fundamental properties of such two-phase flows is of interest since many industrial applications and other boundary-layer flows are characterized by particle transport close to a surface. Snow transport and the snow distribution has been measured, described and estimated intensively in, for example, the sub-Arctic and Arctic (e.g. Pomeroy et al. 1997; Déry and Yau 2001; Gordon et al. 2010; Sturm and Stuefer 2013), Antarctic (e.g. Schmidt 1982; Mann et al. 2000; Nishimura and Nemoto 2005; Lenaerts and van den Broeke 2012) and mountainous terrain (e.g. Winstral and Marks 2002; Doorschot et al. 2004; Schneiderbauer and Prokop 2011; Vionnet et al. 2013). For snow transport simulations many models assume that saltation evolves to a steady state and can be estimated based on mean flow fields. This model approach has been successfully used to describe the change in snow distribution on scales of several metres during storms (see e.g. Lehning et al. 2008). Limitations of this approach, however, are especially recognized in complex terrain. For example, mean-flow-based model descriptions of snow accumulations have been shown to overpredict accumulation in cornices (e.g. Groot Zwaaftink et al. 2013). More importantly, although the use of mean flow fields is necessary for long simulations in large areas, it is a major simplification of the drifting snow process.

High-frequency wind-tunnel (e.g. Guala et al. 2008) and field observations (e.g. Sato and Higashiura 1997; Doorschot et al. 2004) have shown strong fluctuations and intermittency of the snow mass flux on time scales of a few seconds. Knowledge of the causes of this intermittency is, however, limited. To better understand drifting and blowing snow on short time scales the explicit consideration of turbulent wind fields may therefore be necessary. There has been relatively little focus, nonetheless, on modelling intermittent snow transport under the influence of turbulence. Promising attempts into Lagrangian snow transport modelling have been presented by Sato et al. (1997), Sundsbø and Hansen (1997) and Nemoto and Nishimura (2004). The latter included turbulence by a random walk model for the stochastic fluctuation of the vertical wind component. This model, however, was only applicable to flat terrain under moderate winds and cannot be used to analyze the spatial variation of the snow mass flux.

Since the transport of snow and sand is similar in many respects, observations and models of sand saltation can help understand and model drifting snow as well. Similar to snow, observations of sand transport show fluctuations of the mass flux in saltation (e.g. Stout and Zobeck 1997; Butterfield 1998, 1999), which have been connected to turbulent structures (e.g. Sterk et al. 1998). Moreover, several field experiments analyze variations of saltation rates in space and time related to streamers (e.g. Baas and Sherman 2005; Baas 2008; Nield and Wiggs 2011; Ellis et al. 2012). Furthermore, attempts have been made to model sand transport under the influence of turbulence. Turbulence was included in saltation and suspension models by parametrizations (e.g. Kok and Renno 2009) or by calculating particle trajectories using large-eddy simulation (LES, e.g. Shao and Li 1999; Vinkovic et al. 2006; Tong and Huang 2012). Model results of Tong and Huang (2012) showed a fluctuating mass flux in time and an increase of these fluctuations with increasing wind speed; they suggested that these fluctuations are a result of the interaction between the airflow and the particles.

How streamers or other forms of small-scale spatial variation of the mass flux in aeolian transport can affect the local mass-flux time series and cause strong fluctuations has, to our knowledge, not been the topic of previous model studies. Only a few direct numerical simulation (DNS) studies on particle-laden channel flows (Soldati 2005) show the formation of such structures. Model studies may further help to gain understanding in aeolian transport as high-frequency and high-resolution observations are difficult and model studies may be better 
suited to distinguishing the influence of different processes. Furthermore, high-resolution snow transport models accounting for turbulence are expected to allow better estimates of the snow distribution in mountainous terrain in the long term.

We now aim to find a model approach that is able to describe fluctuations or intermittency of drifting snow on short time scales and the spatial variation of drifting snow in aeolian streamers. Based on earlier work (Overney 2006; Lieberherr 2010) we see much potential in describing intermittent snow transport on small spatial and short time scales by a Lagrangian stochastic model driven with LES flow fields. This study introduces this model framework (Sect. 2) and wind-tunnel and field measurements (Sect. 3), and is applied to a small area of a flat snow cover with homogeneous snow properties (Sect. 4). Model results are then qualitatively compared to observations (Sect. 5). Furthermore, we explore the main mechanism behind the spatial variation of the snow mass flux in a model experiment.

\section{Models}

\subsection{Large-Eddy Simulations}

Wind fields for the drifting snow simulations presented in this study were computed by LES (Deardorff 1972; Moeng 1984; Nieuwstadt and Brost 1986). In LES, subgrid-scale (SGS) motions are parametrized and the large-scale motions are resolved. The parametrization can be based on different SGS models; a popular model was introduced by Smagorinsky (1963), which uses a mixing length approach,

$$
\tau_{i j}^{\text {Smag }}=-2 C_{\mathrm{s}}^{2} \Delta^{2}|\tilde{S}| \widetilde{S_{i j}},
$$

where $\tau_{i j}^{\text {Smag }}$ is the SGS stress tensor, $C_{\mathrm{s}}$ is the Smagorinsky coefficient, $\Delta$ is the filter scale and $S_{i j}$ is the strain rate tensor defined by $S_{i j}=\frac{1}{2}\left(\frac{\mathrm{d} u_{i}}{\mathrm{~d} x_{j}}+\frac{\mathrm{d} u_{j}}{\mathrm{~d} x_{i}}\right)$. A clever choice of $C_{\mathrm{s}}$ is needed to ensure the reliability of the model. It can be assumed constant as first proposed by Lilly (1967) with a value of $C_{\mathrm{s}} \approx 0.17$, but the Germano identity (Germano et al. 1991) allows the use of dynamic models. The scale-invariant models use a second filter to determine the value of $C_{\mathrm{s}}$ based on the resolved scales. Still, if $\Delta$ approaches the integral scale, the scale invariance hypothesis may no longer hold. Thus, a further improvement is the use of a scale-dependent dynamic model (Porté-Agel et al. 2000), where a third filter is implemented to investigate the dependence on filter length and to address this issue. The LES model applied here, EPFL-LES from the Ecole Polytechnique Fédérale de Lausanne, originates from Albertson and Parlange (1999). The subgrid scale is modelled using the scaledependent Lagrangian dynamic subgrid model developed by Bou-Zeid et al. (2005). This was chosen because we also plan for simulations with topography, where the Lagrangian scheme that follows the path lines of fluid schemes is more suitable than methods based on planar averaging. Furthermore, boundary conditions based on the immersed boundary method as described by Chester et al. (2007) allow for simulations over complex topography. For further information on the EPFL-LES we refer to Diebold et al. (2013).

From the EPFL-LES we obtain three-dimensional time dependent fields of the resolved (horizontal) $u$-, $v$ - and (vertical) $w$-wind components and the energy dissipation rate. These are used for calculation of the particle trajectories as described in Sect. 2.2. Moreover, we extract the fluid shear stress at $0.10 \mathrm{~m}$ above the surface as we assume the fluid shear stress here is equal to the surface shear stress. The shear stress is calculated based on fluctuations 
of the horizontal and vertical wind components and the averaging time to obtain the shear stress needs to be adjusted to the simulated flow.

\subsection{Lagrangian Stochastic Model}

With the Lagrangian stochastic model we describe the transport of snow based on particle trajectories. We calculate the snow particle trajectories as influenced by inertia, drag and gravity following,

$$
\mathrm{d} u_{p i}=\left(\frac{3}{4} \frac{C_{\mathrm{D}}}{\mathrm{d}_{p}} \frac{\rho_{\mathrm{f}}}{\rho_{\mathrm{p}}}\left|U_{\mathrm{r}}\right|\left(u_{\mathrm{ri}}+u_{\mathrm{si}}-u_{\mathrm{pi}}\right)-\delta_{i, 3} g\right) \mathrm{d} t
$$

where $i$ denotes the $x$-, $y$ - and $z$-directions parallel, perpendicular and normal to the mean flow, $u_{\mathrm{p}}$ is the particle velocity, $d_{\mathrm{p}}$ is the particle diameter, $\rho_{\mathrm{f}}$ is the density of the fluid, $\rho_{\mathrm{p}}$ is the particle density, $U_{\mathrm{r}}$ is the relative velocity, $u_{\mathrm{r}}$ is the resolved fluid velocity, $u_{\mathrm{si}}$ is the SGS fluid velocity, $g$ is the acceleration due to gravity, and $\mathrm{d} t$ is the particle timestep. The particle timestep depends on the particle size and dissipation rate. The drag coefficient $C_{\mathrm{D}}$ is described as a function of the Reynolds number following Clifton and Lehning (2008). Magnus and Saffman forces are neglected as these were estimated to be small compared to drag (Gauer 1999). Furthermore, electrostatic forces and mass loss due to sublimation are neglected.

\subsubsection{Subgrid-Scale Velocity}

The particle velocity as defined in Eq. 2 is influenced by the SGS fluid velocity along the particle trajectory. We use a formulation described by Weil et al. (2004) to obtain the SGS velocity from the turbulence dissipation rate,

$$
\mathrm{d} u_{\mathrm{si}}=-\frac{1}{\beta} \frac{f_{\mathrm{s}} C_{0} \varepsilon}{2} \frac{u_{\mathrm{si}}}{\sigma_{s}^{2}} \mathrm{~d} t+\frac{1}{2}\left(\frac{1}{\sigma_{\mathrm{s}}^{2}} \frac{\mathrm{d} \sigma_{\mathrm{s}}^{2}}{\mathrm{~d} t} u_{\mathrm{si}}+\frac{\partial \sigma_{\mathrm{s}}^{2}}{\partial x_{i}}\right) \mathrm{d} t+\left(\frac{1}{\beta} f_{\mathrm{s}} C_{0} \varepsilon\right)^{1 / 2} \mathrm{~d} \xi_{i}
$$

where $f_{\mathrm{s}}$ represents the SGS fraction of the total turbulent kinetic energy, $C_{0}=2$ is a dimensionless constant (Thomson 1987), $\varepsilon$ is the turbulence dissipation rate and $\xi$ is drawn randomly from a Gaussian distribution. The coefficient $\frac{1}{\beta}$ was added to account for a reduced correlation time scale of heavy particles compared to the fluid time scale, according to Overney (2006), where $\beta=2$ following Wilson (2000). Furthermore, we use $\sigma_{\mathrm{s}}^{2}=\frac{2}{3}\left(\frac{\varepsilon \Delta}{c_{\varepsilon}}\right)$, where $\Delta$ is the filter width and $c_{\varepsilon}=0.93$ (Weil et al. 2004). For dissipation rates smaller than $0.05 \mathrm{~m}^{2} \mathrm{~s}^{-3}$ we only take the last term of Eq. 3 into account and assume that the influence of the SGS on particle velocity is small.

\subsubsection{Feedback of Saltation on the Airflow}

The feedback of particles on the airflow is currently not explicitly taken into account but parametrized in the wall function. We thereby avoid the heavy computational constraints that would result if the particle code were directly run in the LES model. With the wall function approximation used here, LES flow fields can be used offline to drive the particle code. In the lowest $0.10 \mathrm{~m}$ of the computational domain, we obtain the flow velocity at the location of the particle by extrapolating the 0.10 - $\mathrm{m}$ wind speed of the LES simulations assuming a logarithmic wind profile. Here, we assume that the snow concentration extracts momentum from the boundary layer and therefore describe the roughness length according to Raupach (1991), 


$$
z_{0 \mathrm{~S}}=\left(A_{z} \frac{u_{*}^{2}}{2 g}\right)^{1-\sqrt{r}} z_{0}^{\sqrt{r}}
$$

assuming $A_{z}=0.3$ and $\sqrt{r}=u_{* \mathrm{t}} / u_{*}$, where $u_{* \mathrm{t}}$ is the threshold friction velocity and $u_{*}$ is the fluid friction velocity. The assumed increase in roughness length due to the momentum extraction by saltating particles thus causes a decrease of the wind speed. The turbulent eddies resolved by the LES, however, still penetrate into the saltation layer as the LES flow fields define the upper boundary of the wall function. Above this 0.10 -m thick layer, we assume that particle concentrations are generally too low to significantly affect the flow field. This is confirmed by the results of Vinkovic (2005), showing that the feedback between the flow field and the particle concentration does not affect the mean concentration profile for volume fractions on the order of $10^{-5}$.

\subsubsection{Aerodynamic Entrainment}

Snow can be entrained into the surface layer when the friction velocity is large enough to lift particles. This is determined through a threshold friction velocity $\left(u_{* \mathrm{t}}\right)$ of the form (Bagnold 1941),

$$
u_{* \mathrm{t}}=A \sqrt{\frac{\rho_{\mathrm{p}}-\rho_{\mathrm{f}}}{\rho_{\mathrm{f}}} g d_{\mathrm{p}}} .
$$

Clifton et al. (2006) showed, based on wind-tunnel measurements under various conditions, that the threshold friction velocity can be well predicted for snow if $A=0.2$ is assumed. This value is larger than for dry sand (Bagnold 1941) due to the cohesion or bonds between snow particles. To determine if aerodynamic entrainment occurs, we use the local surface shear stress $(\tau)$ rather than the friction velocity of the flow. This means that even for stationary flows the entrainment rate is spatially varying. We can thus rewrite Eq. 5 using $\tau=\rho u_{*}^{2}$ (e.g. Stull 1988) to describe the threshold shear stress $\tau_{\mathrm{tf}}$,

$$
\tau_{\mathrm{tf}}=A^{2} g d\left(\rho_{\mathrm{p}}-\rho_{\mathrm{f}}\right) .
$$

The number of particles that will be entrained, $N_{\mathrm{ae}}\left(\mathrm{m}^{-2} \mathrm{~s}^{-1}\right)$, then linearly increases with the excess shear stress according to a formulation of Anderson and Haff (1991),

$$
N_{\mathrm{ae}}=\eta_{\mathrm{ae}}\left(\tau-\tau_{\mathrm{tf}}\right) .
$$

We follow the description of the coefficient $\eta_{\text {ae }}$ from Doorschot and Lehning (2002),

$$
\eta_{\mathrm{ae}}=\frac{C_{\mathrm{e}}}{8 \pi d_{\mathrm{p}}^{2}}
$$

where the parameter $C_{\mathrm{ae}}=1.5$. The number of particles $N_{\mathrm{ae}}$ is combined into a parcel for which we further calculate the trajectory, noting that all particles in a parcel have the same size, thus saving computation time compared to calculating single particle trajectories. The parcel is then initiated into the flow at a height of $4 \bar{d}_{\mathrm{p}}$. This initial height is in the range where estimates of initial particle velocity were obtained (Nishimura and Hunt 2000). Additionally, we thereby avoid the region very close to the surface where inaccuracies due to flow-field extrapolation are likely to be largest. This assumption can be adjusted depending on the studied terrain and snow cover properties.

The initial velocity of entrained particles $\left(v_{a e}\right)$ is described using a lognormal distribution with mean value $3.3 u_{*}$. The mean value corresponds to measurements from wind-tunnel 
studies of saltating snow (see Nishimura and Hunt 2000 and references therein). However, this measured value of ejection speeds does not only consider particles that start through aerodynamic entrainment, but also through rebound or splash. Moreover, it is based on a limited series of experiments and does not cover many particle sizes or variations in strength of the flow field. In Sect. 5.2 we therefore discuss how this parameter affects the model results.

The ejection angle is described by a lognormal distribution with a mean value depending on the mean particle size as suggested by Clifton and Lehning (2008) based on several experiments found in literature,

$$
\bar{\alpha}_{e j}=75-55\left(1-\exp \left(\frac{-\bar{d}_{p}}{175 \times 10^{-6}}\right)\right) .
$$

With these initial conditions the trajectory of the parcel starts and is calculated using Eqs. 2 and 3. Once a parcel reaches the surface again several scenarios can occur; the particle may stay at the surface or could rebound into saltation again. Moreover, it is able to eject other snow particles into saltation through splash.

\subsubsection{Rebound}

Some snow particles that impact on the surface may rebound, and the probability that parcels rebound is formulated as,

$$
P_{r}=P_{m}\left(1-\exp \left(-\gamma v_{i}\right)\right)
$$

where $v_{i}$ is the impact velocity and we assume that $\gamma=2$ according to Anderson and Haff (1991) but where the maximum $\left(P_{m}\right)$ is lowered from 0.95 to 0.90 as we assume that rebound is less likely for new snow than for sand. This could be adjusted where compacted snow is simulated. The rebound velocity $\left(v_{r}\right)$ is parametrized as a function of the impact velocity according to Shao and Li (1999), based on Anderson and Haff (1991),

$$
p\left(v_{r}\right)=\frac{1}{h v_{i}^{k}} \exp \left(\frac{-v_{r}}{h v_{i}^{k}}\right),
$$

where we assume $h=0.5$ and $k=1$. This corresponds to an experimental study where the ratio between the rebound and impact velocities of sand was observed to be between 0.5 and 0.6, independent of particle size (Rice et al. 1995). However, we also impose an upper limit of $v_{r} \gtrless v_{i}$ to ensure that energy and momentum are conserved. The ejection angle of rebounding particles is randomly chosen from an exponential distribution with mean value $45^{\circ}$, similar to Kok and Renno (2009).

\subsubsection{Splash}

To estimate the number of particles that are ejected by an impacting particle we follow the energy balance as described by Gauer (1999). Energy is lost due to dissipation and is needed to break bonds between snow particles. Furthermore, part of the impact energy may be used for rebound; the remaining energy is available for splash. We estimate the velocity of ejected particles using a similar distribution as for rebound (Eq. 11), but with $h=0.25$ and $k=0.3$ (Shao and Li 1999). The size of ejected particles is randomly taken from the size distribution of the snow-cover particles. Knowing the energy available for ejection and the velocity of ejected particles we can determine the mass and number of particles that will be 
Fig. 1 Drifting snow observation site near Weissfluhjoch

Versuchsfeld

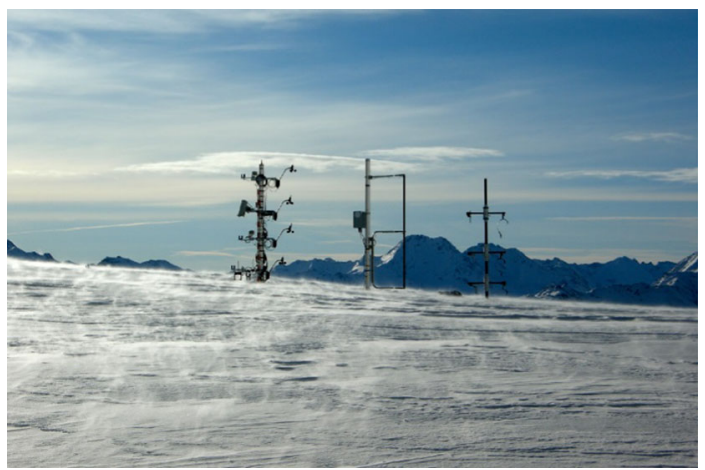

ejected. However, Kok and Renno (2009) argued that momentum rather than energy is mostly restricting particle splash. Indeed we found that, using the parameters above, momentum is often added to parcels. In those cases we lower the speed of ejected particles such that momentum is conserved and consider the excess energy as lost. The angle of ejected particles is described by an exponential distribution of mean value $50^{\circ}$ (Kok and Renno 2009).

\section{Observations}

\subsection{Field Experiment}

In winter 2011 and 2012 measurements of the drifting snow mass flux were obtained close to the SLF Weissfluhjoch Versuchsfeld at $2540 \mathrm{~m}$ above sea level near Davos, Switzerland $\left(46^{\circ} 49^{\prime} 45.64^{\prime \prime} \mathrm{N}, 9^{\circ} 48^{\prime} 34.98^{\prime \prime} \mathrm{E}\right)$. Mass flux was measured downwind of a relatively smooth, undisturbed, gently sloped field (slope angle $<5^{\circ}$ ) of approximately $30 \mathrm{~m}$ (see Fig. 1). This field is located in mountainous terrain where surrounding topography is likely to influence turbulence characteristics at the field site. Previous measurements of drifting snow at this location were reported by Doorschot et al. (2004). Besides snow mass-flux measurements, observations include vertical profiles of temperature, humidity and wind over approximately $2 \mathrm{~m}$. Moreover, snow height and snow-cover properties such as snow density were measured. The snow mass flux was measured with several sensors; in this study, however, we will only present measurements from a snow particle counter (SPC, e.g. Sugiura et al. 1998) with a resolution of $1 \mathrm{sec}$. The SPC determines the snow mass flux in a volume of $25 \times 10^{-9} \mathrm{~m}^{3}$, and was adjusted in height according to the interest of specific measurement periods and in the measurements presented here was placed $0.06 \mathrm{~m}$ above the surface. 10 -s average values of the wind speed and wind direction were measured with cup anemometers placed about 0.35 , $0.95,1.50$ and $2.10 \mathrm{~m}$ above the surface. Most important properties of the selected drifting snow event used for a comparison with a model simulation are given in Table 1.

\subsection{Wind Tunnel}

Apart from field measurements, observations of snow mass flux were obtained in the SLF wind tunnel in Davos, see e.g. Clifton et al. (2006) for a description. Snowfall was collected in trays outside the wind tunnel to obtain a natural snowpack, and the trays were subsequently placed in the wind tunnel for drifting snow experiments. The wind tunnel comprises a con- 
Table 1 Friction velocity, threshold friction velocity and sensor properties in the simulation and field experiments

\begin{tabular}{llll}
\hline & Field & Wind tunnel & Simulation \\
\hline Friction velocity $\left(\mathrm{m} \mathrm{s}^{-1}\right)$ & 0.43 & 0.26 & 0.45 \\
Threshold friction velocity $\left(\mathrm{m} \mathrm{s}^{-1}\right)$ & 0.32 & 0.17 & 0.37 \\
Sampling area $\left(\mathrm{m}^{2}\right)$ & $5.0 \times 10^{-5}$ & $3.5 \times 10^{-3}$ & $1.0 \times 10^{-3}$ \\
Sensor height $(\mathrm{m})$ & 0.06 & 0.03 & 0.03 \\
Sensor type & SPC & PTV & Virtual particle counter
\end{tabular}

The threshold friction velocity was determined based on wind-profile measurements in the field and wind tunnel and calculated based on the particle size (Eq. 5) for the simulation. The sampling area is the area of the sensor measurement volume perpendicular to the flow

traction through which air from outside is entrained and led through a $6 \mathrm{~m}$ flow conditioning section with four regularly spaced spires of height $0.50 \mathrm{~m}$ of triangular shape and base length $0.05 \mathrm{~m}$. Additional roughness elements of width $0.03 \mathrm{~m}$, height $0.01 \mathrm{~m}$ and length $0.015 \mathrm{~m}$ with a density of 190 per $\mathrm{m}^{2}$ were mounted on the floor. The flow conditioning section was followed by an 8-m long section with a floor that can be adjusted in height to obtain a smooth transition to the snow surface, and on which the snow trays are placed. The ceiling of the wind tunnel was adjusted in height so that the pressure change along the test section was below $5 \mathrm{~Pa}$ at $10 \mathrm{~m} \mathrm{~s}^{-1}$. The mean airflow of the free stream was measured approximately $0.70 \mathrm{~m}$ above the snow cover by a mini air-fan anemometer.

The snow mass flux is inferred over a roughly $1.4 \times 10^{-4} \mathrm{~m}^{3}$ volume placed towards the end of the wind tunnel by a two-dimensional high speed imaging system (FlowMaster 2D PTV/PIV, LaVision) and image analysis using the software DaVis (LaVision). Every $2 \mathrm{~s}$ two consecutive images were recorded with a delay of $0.25 \mathrm{~ms}$. On these images the shadows of the particles were recorded and the size and velocity of the particles could be retrieved. The depth of field for the shadowgraphically imaged particles is proportional to their size (LaVision DAVIS manual), hence the depth of field needs to be known to measure particle size distributions and concentration or fluxes. This was performed by taking images of blobs of known and different sizes printed on a transparent sheet and varying the distance to the camera. Then the particle detection algorithm was applied to these images and in that way for each particle size the depth range for which the particles were detected was obtained. Consequently, the snow mass flux could be determined. Some properties of the selected wind-tunnel experiment shown in the results section are given in Table 1.

\section{Simulation Set-Up}

The simulations presented herein are pertained for a flat area of $12.8 \mathrm{~m}$ by $6.4 \mathrm{~m}$ on a spatial resolution of $0.10 \mathrm{~m}$; the vertical extent of the model domain is $6.4 \mathrm{~m}$. A stress-free boundary condition is prescribed at the top of the domain and the lateral boundary conditions require a special treatment. The LES runs are driven by a pressure gradient, using spectral methods whose periodicity is assumed. It is known that these kind of boundary conditions might influence coherent flow structures (Davidson 2004, p. 433), but their accurate quantitative prediction is beyond the scope of the current study. The bottom boundary was a no-slip rigid wall, on which the SGS fluxes were evaluated from resolved variables at the lowest level, using the prescribed aerodynamic roughness length $\left(z_{0}\right)$. An instantaneous logarithmic 
Table 2 Overview of parameters in the LES simulations

\begin{tabular}{ll}
\hline Parameter & Value \\
\hline Domain size & $12.8 \times 6.4 \times 6.4 \mathrm{~m}^{3}$ \\
Horizontal resolution $(d x, d y)$ & $0.1 \mathrm{~m}$ \\
Vertical resolution $(d z)$ & $0.1 \mathrm{~m}$ \\
$\begin{array}{l}\text { Time interval for extraction of } \\
\text { resolved wind components }\end{array}$ & $0.01 \mathrm{~s}$ \\
Averaging time for surface shear stress & $0.1 \mathrm{~s}$ \\
Height extracted surface shear stress & $0.1 \mathrm{~m}$ \\
Friction velocity $\left(u_{*}\right)$ & $0.45 \mathrm{~m} \mathrm{~s}^{-1}$ \\
Roughness length $\left(z_{0}\right)$ & $3 \times 10^{-4} \mathrm{~m}$ \\
Fluid density & $1.34 \mathrm{~kg} \mathrm{~m}^{-3}$ \\
\hline
\end{tabular}

profile near the ground surface was assumed. We simulate snow transport over this model domain for a period of $45 \mathrm{~s}$, and for this simulation we repeat a set of LES wind fields covering $15 \mathrm{~s}$. The resolved wind components were obtained with a frequency of $100 \mathrm{~Hz}$ and the shear stress is based on a 0.1-s averaging time. For this averaging time and a freestream velocity of $11 \mathrm{~m} \mathrm{~s}^{-1}$ in the current simulations we can thus roughly capture the shear stress induced by 1-m large eddies, as can be inferred from multiplying the averaging time by the freestream velocity. The averaging time to obtain the shear stress needs to be adjusted to the simulated flow. For further details on the LES simulation see the parameter specification in Table 2 .

Not only for the large-eddy simulation but also for the Lagrangian stochastic model several parameters need to be defined, in addition to the fixed parameters given in the model description (Sect. 2.2). As mentioned in Sect. 2.2.3 we combine particles into parcels. For the current simulations, we specify an entrainment frequency of $10 \mathrm{~Hz}$ and an entrainment area per parcel of $1 \times 10^{-3} \mathrm{~m}^{2}$, implying that the parcels contain particles that could entrain over $0.1 \mathrm{~s}$ taken from an area of $1 \times 10^{-3} \mathrm{~m}^{2}$. This area size was chosen to limit the computation time but at the same time maintain a high resolution. The location of aerodynamic entrainment areas is randomly picked throughout the model domain. For the simulations presented in this study, parcels that start from entrainment contain on average about 15 particles. In the current simulations that should represent transport of fresh snow, the mean snow particle diameter at the surface is $0.5 \times 10^{-3} \mathrm{~m}$ and the particle size is described with a gamma distribution as observed for drifting snow (Schmidt 1982). Note that this is the particle size distribution for the available snow on the surface; for each parcel we randomly choose a size from this distribution and all particles in a parcel have the same size. We further assume that $10 \%$ of the impact energy is lost due to dissipation. Moreover, we assume that $10^{-8} \mathrm{~J}$ is needed to break the bonds of a single snow cover particle (Gauer 1999). This parameter needs to be adjusted to the snow type since new snow is less prone to be ejected than compacted snow (Sugiura and Maeno 2000).

When parcels leave the domain through the boundary perpendicular to the main flow, they are inserted again with their current velocity at the inflow boundary at their previous altitude and a randomly picked location in the $y$-direction. Parcels that leave the domain through a side boundary are lost from the simulation and snow cover. Finally, we place virtual sensors of a size equal to the parcel area at several locations in the domain to obtain the snow mass flux and compare this to the field and wind-tunnel observations (also see Table 1). An overview of parameter values for the current simulation of fresh snow is given in Table 3. 
Table 3 Overview of parameters in the Lagrangian stochastic model that may be adjusted to the simulated snow-cover type

\begin{tabular}{|c|c|c|c|}
\hline & $\begin{array}{l}\text { Simulations } v_{a e} \\
\text { (Sect. 5.2) }\end{array}$ & $\begin{array}{l}\text { Simulated } \\
\text { fluctuations } \\
\text { (Sect. 5.4, 5.5) }\end{array}$ & $\begin{array}{l}\text { Simulations } u_{* t} \\
\text { (Sect. 5.7) }\end{array}$ \\
\hline Duration (s) & 15 & 45 & 10 \\
\hline Mean particle diameter $\left(\bar{d}_{p}, \mathrm{~m}\right)$ & $0.5 \times 10^{-3}$ & $0.5 \times 10^{-3}$ & $\begin{array}{l}1.0 \times 10^{-3}- \\
0.55 \times 10^{-3}\end{array}$ \\
\hline $\begin{array}{l}\text { Particle size } \\
\text { distribution }\end{array}$ & $\begin{array}{c}\gamma \text {-distribution } \\
\alpha=2 \\
\beta=\bar{d}_{p} / \alpha\end{array}$ & $\begin{array}{c}\gamma \text {-distribution } \alpha= \\
2, \beta=\bar{d}_{p} / \alpha\end{array}$ & Fixed size \\
\hline Entrainment frequency $(\mathrm{Hz})$ & 10 & 10 & 100 \\
\hline Entrainment area per parcel $\left(\mathrm{m}^{2}\right)$ & $0.1 d x d y$ & $0.1 d x d y$ & $0.5 d x d y$ \\
\hline Initial height particles (m) & $4 \bar{d}_{p}$ & $4 \bar{d}_{p}$ & $4 \bar{d}_{p}$ \\
\hline Entrainment velocity $\left(v_{a e}\right)$ & $0.33 u_{*}-16.5 u_{*}$ & $3.3 u_{*}$ & $3.3 u_{*}$ \\
\hline Energy lost to dissipation (\%) & 10 & 10 & 10 \\
\hline Maximum probability rebound $\left(P_{m}\right)$ & 0.90 & 0.90 & 0.90 \\
\hline Energy bonds $(\mathrm{J})$ & $10^{-8}$ & $10^{-8}$ & $10^{-8}$ \\
\hline
\end{tabular}

\section{Results and Discussion}

\subsection{Surface Shear Stress}

The use of the surface shear stress obtained with the LES rather than a constant friction velocity, as explained in Sect. 2.2.3, may have a large influence on the aerodynamic entrainment rate. We therefore briefly show and discuss this LES model result. Despite the flat terrain the surface shear stress strongly varies in space, as can be seen in the shear stress at two timesteps shown in Fig. 2. The structures or regions of larger or lower shear stress do not remain fixed at their location but are constantly developing and cross the domain approximately with the mean flow.

Doorschot et al. (2004) already concluded that they needed a distribution of the shear stress, rather than a mean friction velocity, to obtain good model results of the snow mass flux compared to field measurements. The probability distribution of the surface shear stress in our simulations, over all simulated timesteps and grid points, is shown in Fig. 3. This distribution shows a good correspondence to measurements of Alfredsson et al. (1988), and the good comparison indicates that we use realistic values as input to the snow transport model. However, we also find that the distribution is relatively narrow. The ratio between the root-mean square and the mean value of the shear stress obtained with the LES is only 0.17; this ratio is lower than values obtained in measurements by Alfredsson et al. (1988) of 0.4. This underestimation may be explained due to different factors: we may miss the influence of larger eddies on the surface shear stress since we chose a relatively short averaging time to calculate shear stress from the LES (see Sect. 2.1). Additionally, the influence of small scales that are not captured by the LES on the modelled surface shear stress is added based on a SGS parametrization and this may also not fully capture surface-stress variability.

\subsection{Sensitivity Analysis of Initial Particle Velocity}

The initial velocity of entrained snow particles is difficult to measure and consequently only experiments on the combination of entrainment, rebound and splash have been done (e.g. 

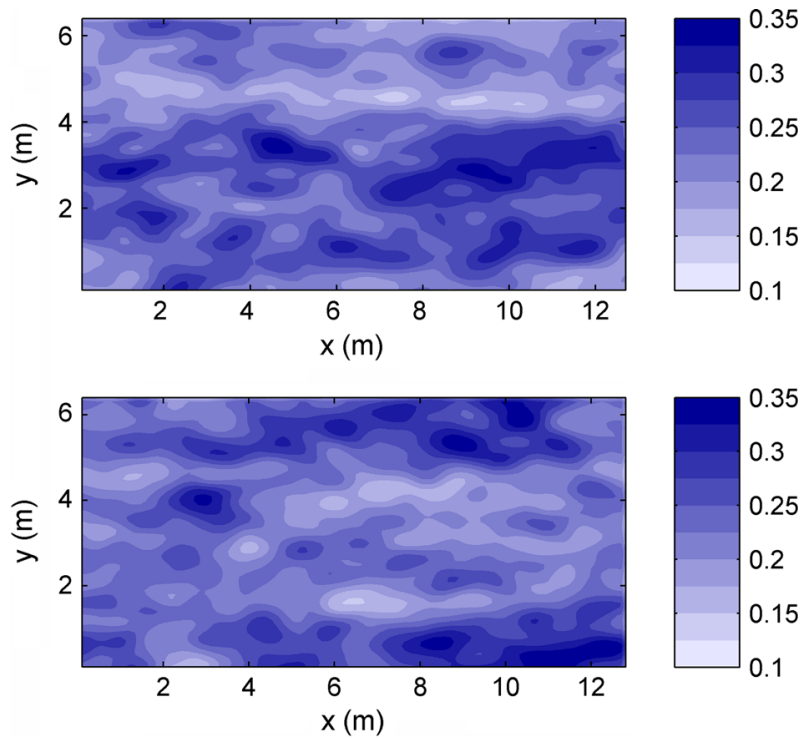

Fig. 2 Surface shear stress $\left(\mathrm{N} \mathrm{m}^{-2}\right)$ : 0.1-s mean value after about $8 \mathrm{~s}$ (top) and $12 \mathrm{~s}$ (bottom) of LES simulation

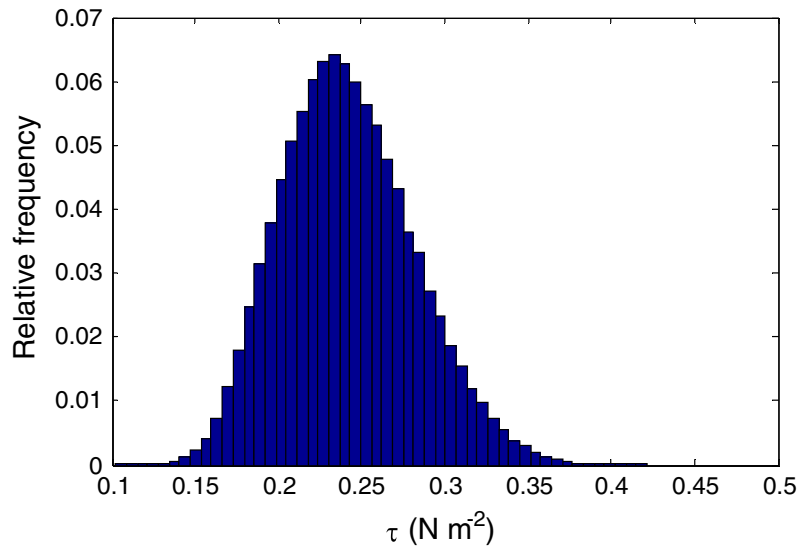

Fig. 3 Frequency distribution of shear stress obtained from the LES, covering the complete simulation time and domain

Araoka and Maeno 1981; Nishimura and Hunt 2000). Nonetheless, these estimates are the basis of a parameter in our model simulations. Given the uncertainty of this parameter, we now aim to describe how the initial entrainment velocity influences the model results. A sensitivity analysis where we only varied the initial velocity of the entrained particles $\left(v_{a e}\right)$ showed that the total mass of airborne particles $\left(m_{a p}\right)$ increased nearly linearly with the initial velocity of the particles (Fig. 4).

The sensitivity of the total mass of airborne particles to this parameter is large because it determines part of the particle's kinetic energy. Particles that start with high speeds remain longer in the air than slower particles, have a larger probability to rebound and more energy may be available to eject other particles. These factors contribute to an increasing snow 
Fig. 4 Total mass of airborne particles (averaged over $13 \mathrm{~s}$ after a 2-s spin-up to equilibrium saltation) versus the mean entrainment velocity, both standardized to the respective values in the reference simulation where $\bar{v}_{a e, r e f}=3.3 u_{*}$

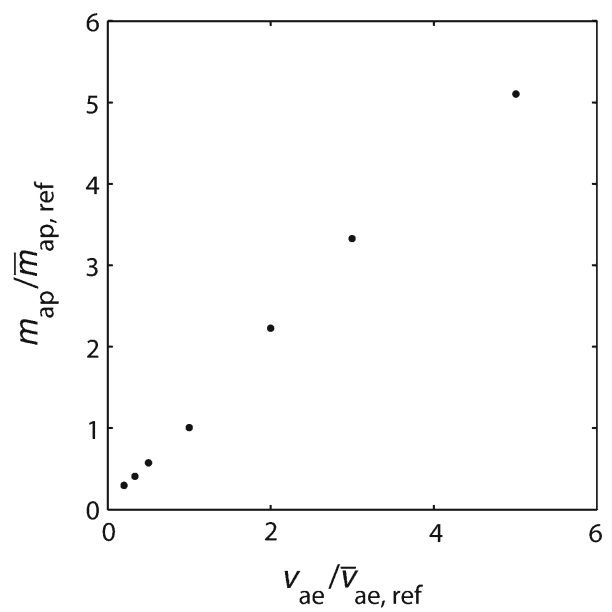

concentration when increasing the initial particle speed. Furthermore, it takes more time to reach an equilibrium state for larger initial velocities as the flight time of particles increases. The sensitivity of the model to the initial velocity of the particles thus shows the need for reliable measurements of this parameter over a range of snow and flow conditions. Alternatively, we expect that a direct feedback of the particles on the flow field can reduce the sensitivity of the snow transport model to this particular parameter since unrealistically large snow amounts would extract momentum from the flow and subsequently reduce wind speed. A reduced wind speed will consequently limit entrainment, rebound and splash rates. This is not possible with the current feedback based on the increasing roughness length, as it is not directly influenced by the snow concentration. The sensitivity of the model to the initial particle velocity indicates a limited quantitative applicability of the model but should not affect our qualitative results on the spatial and temporal variability of drifting snow.

\subsection{Vertical Profile of Modelled Snow Mass Flux}

The presented model was developed to study drifting snow behaviour on short time scales with a strong focus on qualitative results. However, such a model should also be able to represent mean snow-transport profiles. For the chosen reference simulation, which will be used to study snow mass-flux fluctuations below, we therefore also show a vertical profile of the snow mass flux in Fig. 5. This is a mean profile of 30 randomly picked locations in the model domain and the values are relative to the mean snow mass flux obtained at the lowest virtual sensors. The snow mass-flux profile appears to be in agreement with wind-tunnel measurements such as presented by Guala et al. (2008). We can confirm this based on the analysis of Nishimura and Hunt (2000) who showed that observed mass-flux profiles were of the form,

$$
Q(z)=a_{m}\left(u_{*}-u_{* \mathrm{t}}\right)^{3} \frac{\lambda g}{u_{*}^{2}} \exp \left(\frac{-\lambda g z}{u_{*}^{2}}\right)
$$

where $Q$ is the snow mass flux at height $z, a_{m}$ is a constant and $\lambda$ is a parameter that relates the length scale of the saltation system $L$ to the height particles reach according to $L=\frac{u_{*}^{2}}{\lambda g}$. In a relative vertical profile, we can determine $\lambda$ independent of assumptions of $a_{m}$, as has 
Fig. 5 Vertical profile of the modelled snow mass flux (*), relative to the snow mass flux at the lowest virtual sensor. The dotted line is the relative mass flux according to Eq. 12 assuming $\lambda=0.78$

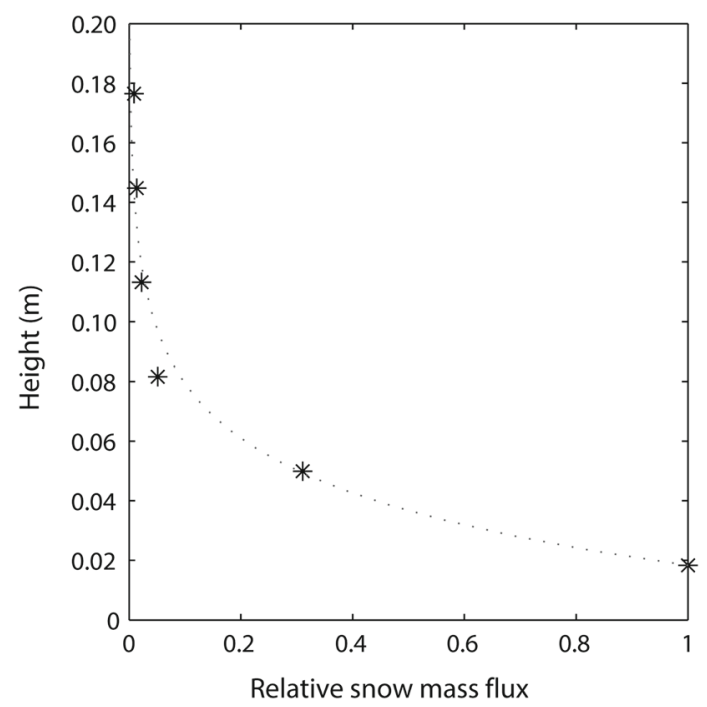

also been done by Guala et al. (2008). For the current simulation, we found $\lambda \approx 0.78$, a value that is in the range determined from observations by Guala et al. (2008) for a mixed saltation-suspension regime and can vary depending on particle sizes (Nishimura and Hunt 2000). We may therefore conclude that the model can replicate a reliable mean vertical profile with the current settings and parameter assumptions.

\subsection{Modelled and Observed Time Series of Snow Mass Flux}

Field observations of drifting snow are usually made in the form of time series of the snow mass flux at a single point (e.g. Doorschot et al. 2004). We retrieved the snow mass flux at several locations in our model domain by virtual sensors that are supposed to mimic particle counters (also see Sect. 4 describing the simulation set-up). We present time series of the snow mass flux (Fig. 6) at two points in the model domain located $2 \mathrm{~m}$ apart from each other in the direction perpendicular to the mean flow at a height of $30 \mathrm{~mm}$. Sensor A is located at ( $\mathrm{x}$ $=10 \mathrm{~m}, \mathrm{y}=5 \mathrm{~m}), \mathrm{B}$ at $(\mathrm{x}=10 \mathrm{~m}, \mathrm{y}=3 \mathrm{~m})$, as also shown in Fig. 9. First, we can conclude that the combination of LES flow fields and a Lagrangian stochastic model is able to reproduce a signal of fluctuating drifting snow (Fig. 6). While the mass of airborne particles in the domain quickly reaches an equilibrium state and shows only small fluctuations, the local mass flux at sensors A and B can vary by orders of magnitude within seconds despite the stationary flow and small fluctuations in the shear stress.

The friction velocity and snow particle size assumed in the model simulation are comparable to those of field measurements shown in Fig. 7 (also see the properties given in Table 1). Comparing the mean mass flux over these periods, we find that the simulated and observed mean snow mass fluxes are on the same order of magnitude. The mean snow mass flux, however, can also be estimated by simpler models and is therefore not the topic of discussion here. A novelty of this model is the possibility of simulating fluctuations on short time scales, which is why we rather focus on these results. Therefore, we now qualitatively compare the modelled time series of snow mass flux, first to these measurements obtained at Weissfluhjoch Versuchsfeld and later to wind-tunnel observations. The wind speed measured at about $0.35 \mathrm{~m}$ above the snow surface and the snow mass flux (at approximately $0.06 \mathrm{~m}$ ) are 

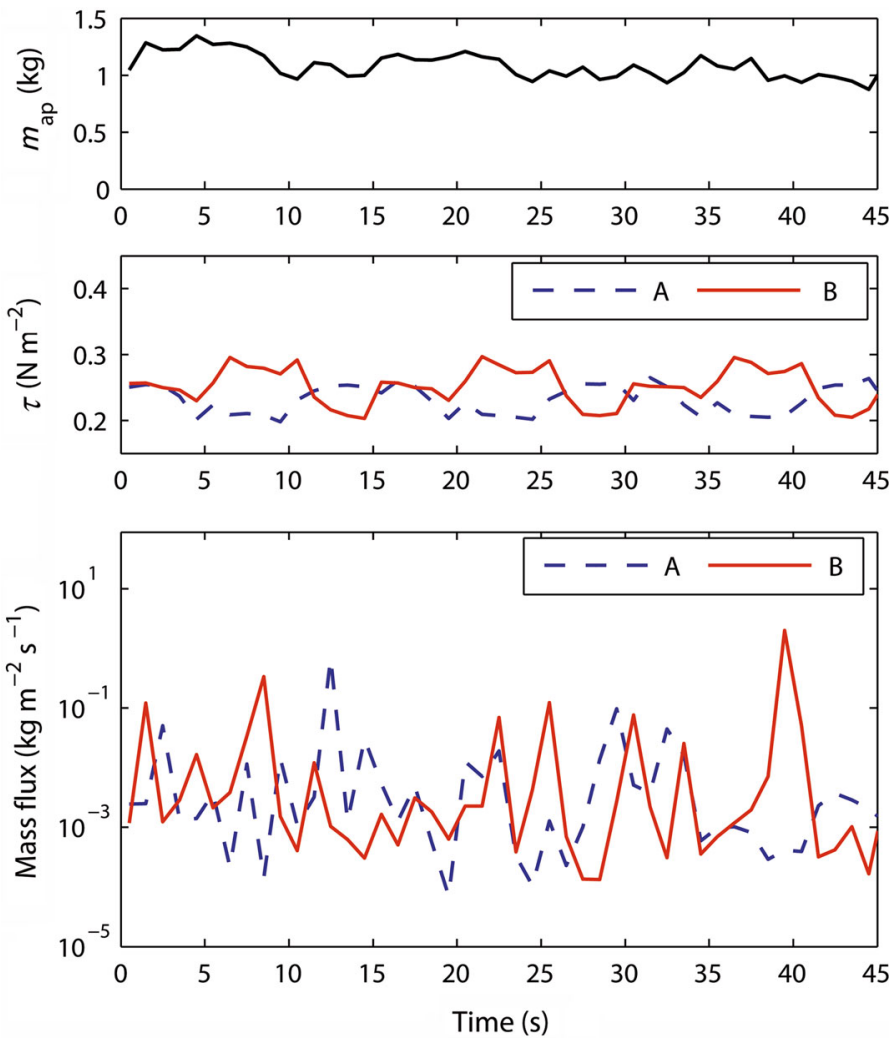

Fig. 6 Time series of the 1-s mean total mass of airborne particles in the model domain (top), 1-s mean shear stress at virtual sensors A and B (middle) and 1-s mean snow mass flux at A and B (bottom)

shown over a period of $15 \mathrm{~min}$ (Fig. 7, top and middle panel), and which show fluctuations in the snow mass flux of several orders of magnitude. To allow a comparison with the shorter simulation shown in Fig. 6, a selection of three shorter measurement series is also given (Fig. 7, bottom). The fluctuations of the measurements over these short periods are smaller than those shown in the model results. This is confirmed by the smaller coefficient of variation, ranging from 1.1 to 2.7 for the three measurement series. The coefficient of variation of the snow mass-flux time series for the field measurements and model simulations are on the same order of magnitude, even though the model does not account for all influences present in the measurements, such as the heterogeneity of snow-cover properties and a wind field that is influenced by the surrounding topography. The observed difference in coefficients of variation is likely due to the length scales of structures in snow transport as will be discussed in Sect. 5.5.

Furthermore, we compare the model results to wind-tunnel measurements of the snow mass flux (Fig. 8). Here, we only include measurements made briefly after the initiation of drifting snow. Therefore, the snow properties can still be considered homogeneous and surface features have not developed yet. Fluctuations in the snow mass flux are clearly smaller in the wind-tunnel experiment than in model results and field observations. Several factors are a cause of this difference: first of all, the measurement system in the wind tunnel determines the snow mass flux in a volume much larger than that of the SPC or virtual 

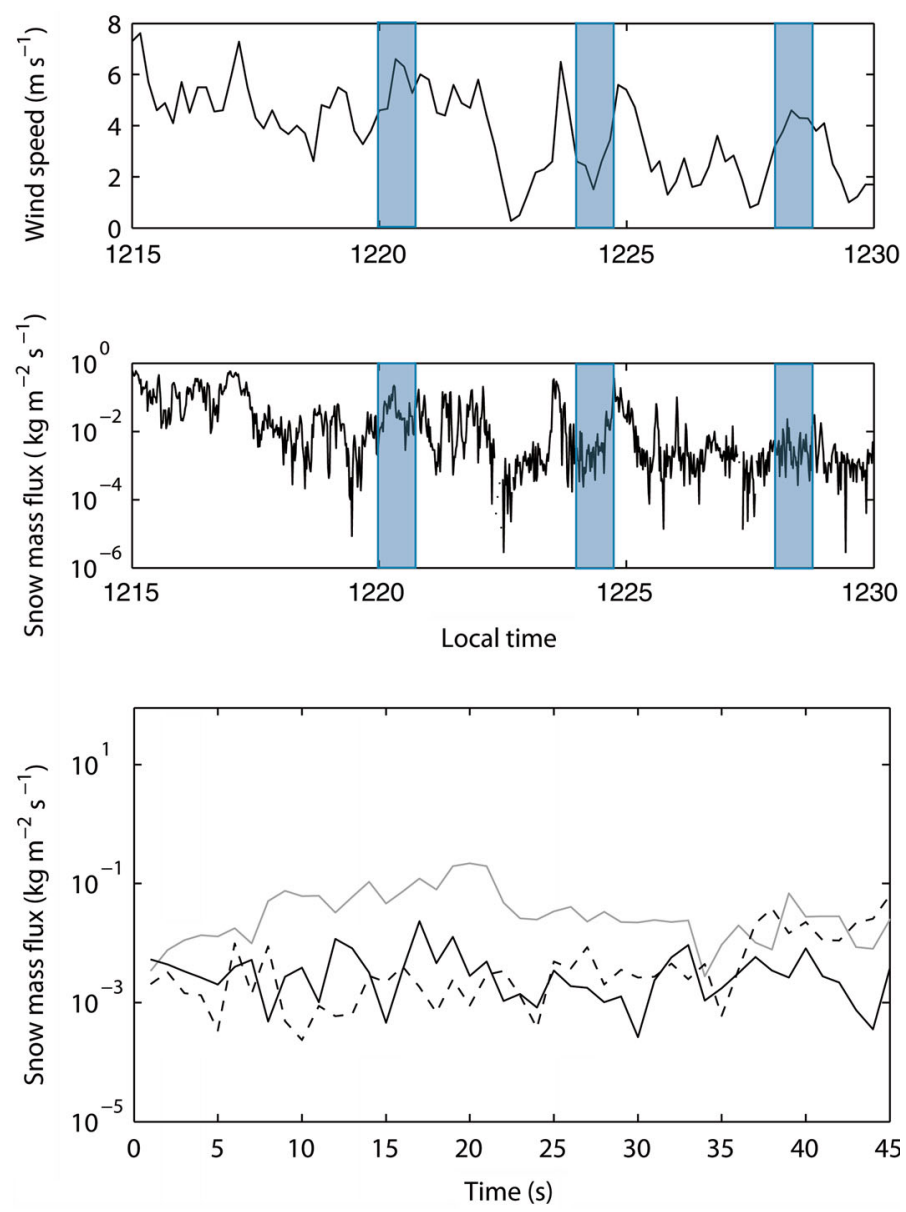

Fig. 7 Observed wind speed at $0.35 \mathrm{~m}$ above the snow surface (top panel), the observed snow mass flux (middle panel) and a selection of snow mass-flux measurements over $45 \mathrm{~s}$ (bottom panel) for a qualitative comparison with Fig. 6. The blue areas in the upper panels indicate the measurement periods shown in the bottom panel. All measurements were made at Weissfluhjoch Versuchsfeld on 24 January 2012 after a period of snowfall

sensor. This means that spatial variations on small scales that influence both model and field estimates may be averaged out in the wind-tunnel observations. Note also that wind-tunnel measurements of snow mass flux obtained with an SPC (e.g. Guala et al. 2008) appear to have stronger fluctuations than the PTV measurements shown in Fig. 8, since the measurement volume is smaller. Furthermore, we need to consider that fluctuations in the model may be overpredicted to some extent due to the lack of a direct feedback of the particles on the flow, which would, for instance, restrict further entrainment where snow mass fluxes become too large to be supported by the flow. Another cause that may contribute to larger fluctuations in the modelled snow mass flux is the combination of particles into parcels. Snow mass-flux fluctuations in the wind tunnel are expected to be smaller than in the field since the flow is kept relatively steady. Finally, coherent turbulent structures that influence drifting snow are, due to the smaller Reynolds number, less developed in the wind tunnel than in the field. 


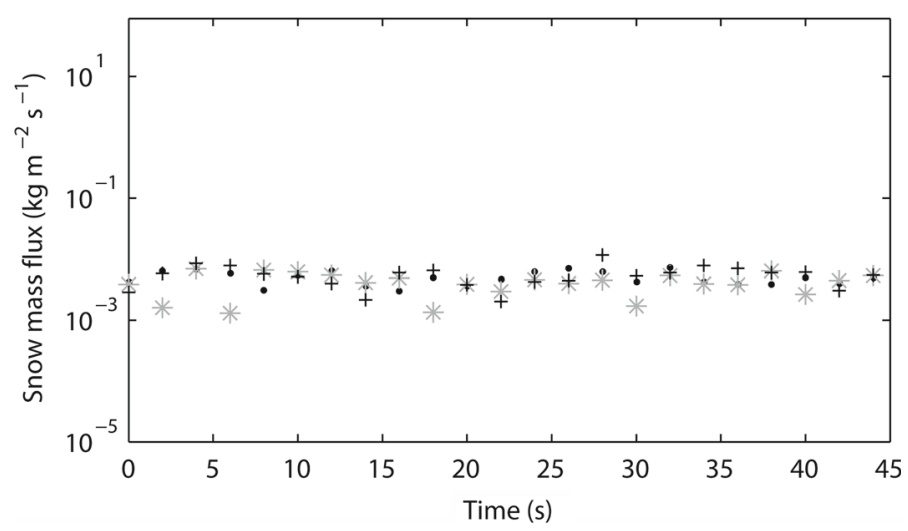

Fig. 8 Three 45-s time series of snow mass flux measured in the SLF wind tunnel. The axes correspond to those in Figs. 6 and 7 (bottom) to allow a qualitative comparison

\subsection{Spatial Variation of Snow Parcel Concentration}

The fluctuations of the modelled snow mass flux are caused by several factors. Although on very short time scales some variation in the modelled snow mass flux is due to the combination of particles into parcels, this effect should be limited in the 1-s average values presented in Fig. 6. We expect that the spatial distribution of the snow parcels can mostly explain the fluctuations in the modelled snow mass flux, and we select two cases where we can compare the snow mass fluxes at the two virtual sensors. First of all, around 8-9 s after the start of the simulation there is a strong peak in the snow mass flux at sensor B while at sensor A the snow mass flux is small. Looking at the position of all parcels around this timestep (see Fig. 9, top panel), we indeed find that there is a cluster of parcels located at B while $2 \mathrm{~m}$ away at sensor A there are only a few parcels present. The opposite is seen a few seconds later (Fig. 9, bottom panel). At that time (12-13 s), not only the pattern or spatial distribution of snow parcels has changed, there also seems to be less airborne parcels in general, which is possible due to changes in the surface shear stress. We correspondingly find a peak in snow mass flux at sensor A and a moderate snow mass flux at sensor B (Fig. 6). We can thus relate the presence of such spatial clusters or structures in snow parcel concentration to peaks in the snow mass flux. These structures of snow parcels are phenomena observed in drifting snow (see, for example, Fig. 1) and sand (e.g. Baas and Sherman 2005) and are comparable to DNS results of particle dispersion close to the surface presented by Soldati (2005). However, we also recognize that the streamers in Fig. 1 appear to be of a smaller scale than the modelled structures (Fig. 9). This can further explain the relatively large modelled coefficient of variation discussed in the previous section. The SPC measurements are 1-s averaged values, as are the values of modelled snow mass flux, but the length scale of the simulated structures is larger than the length scale of the observed streamers. We can roughly estimate the sensor passing time based on the length scale and particle speed. In the field measurements we estimate that length scales are around $0.5 \mathrm{~m}$ and the speed about $2 \mathrm{~m} \mathrm{~s}^{-1}$, and from this we derive a passing time of $0.25 \mathrm{~s}$. This is smaller than the sampling time $(1 \mathrm{~s})$. In the simulations on the other hand, we estimate a length scale of roughly $3 \mathrm{~m}$ and a mean particle speed of $3 \mathrm{~m} \mathrm{~s}^{-1}$ leading to a passing time of $1 \mathrm{~s}$ that is equal to the sampling time. Hardalupas and Horender (2001) have addressed the influence of the sampling time on the coefficient of variation and shown how it can strongly decrease with sampling time. Therefore, to compare the coefficients of variation 

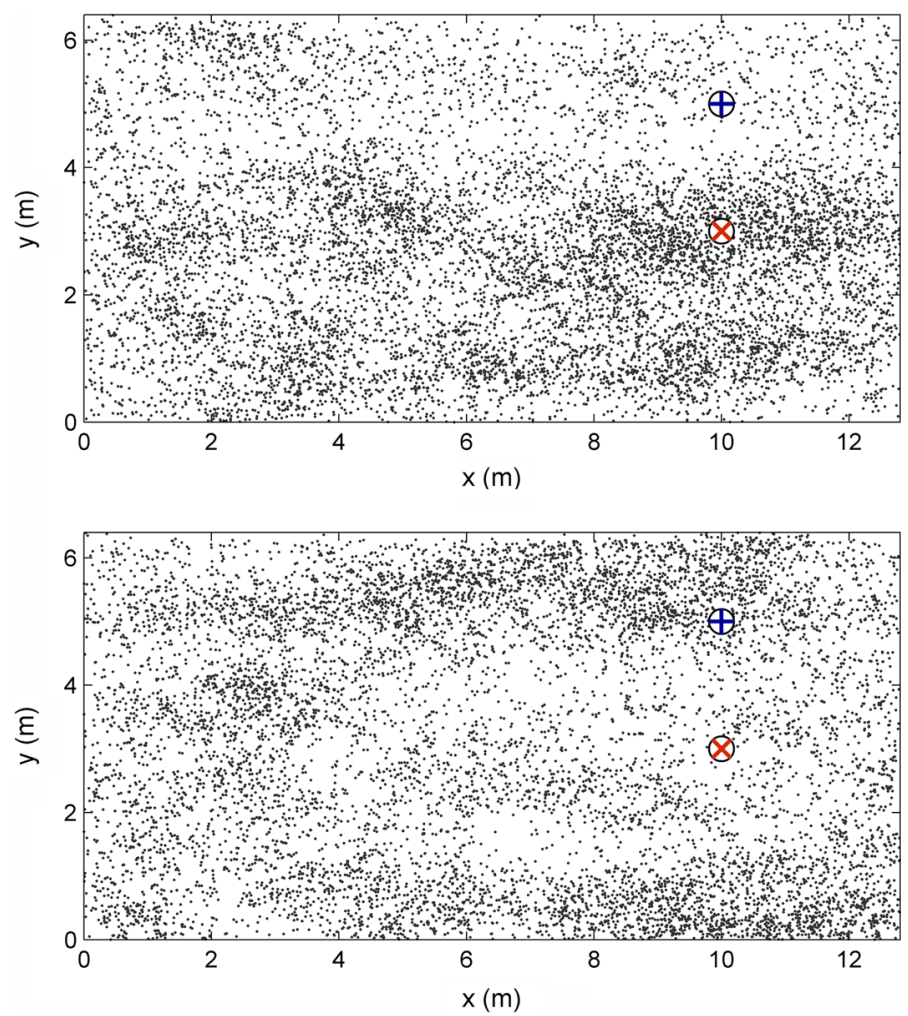

Fig. 9 The location of all parcels about $8 \mathrm{~s}$ (top) and $12 \mathrm{~s}$ (bottom) after the start of the simulation. The crosses indicate the location of sensors $\mathrm{A}(+$, blue $)$ and $\mathrm{B}(\mathrm{x}$, red $)$

of measurements and simulation we adjusted the sampling time of the simulations such that the ratio of passing to sampling time became equal for field measurements and simulation. The coefficient of variation of the simulated drifting snow mass flux was decreased by almost a factor two from 4.4 to 2.3 when increasing the sampling time to $4 \mathrm{~s}$. This value is now in the range of the observed coefficient of variation (1.1-2.7). Furthermore, this indicates the importance of optimizing the measurement frequency and measurement volume of drifting snow observations to the expected length scales (Hardalupas and Horender 2001).

\subsection{Investigating Causes of the Modelled Spatial Variability of Snow Parcel Concentration}

Streamers seen in field observations may be influenced by many factors, such as the spatial variability of snow properties, and their development cannot be fully understood from point measurements. An understanding of the mechanisms behind the development of the spatial variability of snow mass flux in the current simplified model simulation may therefore also contribute to a better understanding of field observations.

Since the snow cover is flat and the snow-cover properties are spatially homogeneous, the modelled structures or clusters of high parcel numbers can only be caused by convergence and divergence of the airflow, variations in the surface shear stress or the splash process. As simulations without splash (not shown) showed generally lower snow mass fluxes but similar results of the spatial distribution of the parcels as in Fig. 9, this process cannot be a main factor in the development of the structures in our model results. It may, however, help to 

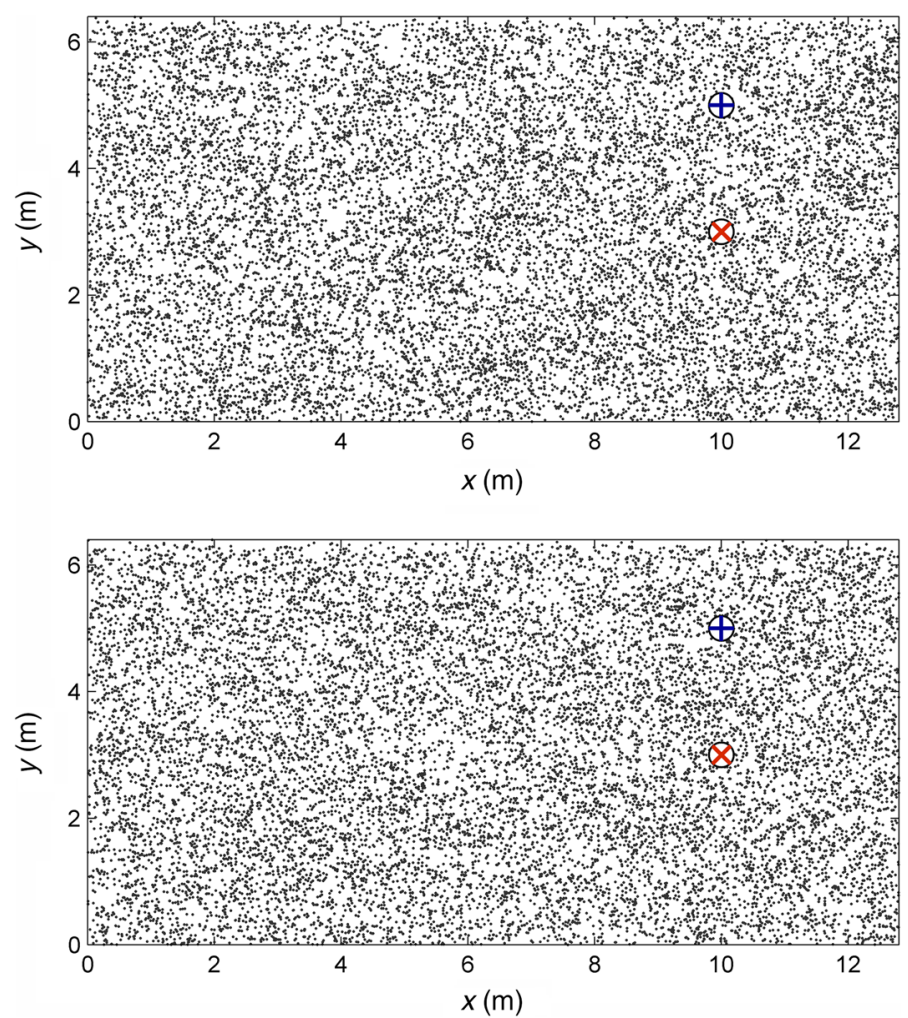

Fig. 10 The location of all parcels around timestep $8 \mathrm{~s}$ (top) and $12 \mathrm{~s}$ (bottom) for entrainment governed by a mean friction velocity. The timesteps correspond to the results shown in Fig. 6 . The crosses indicate the location of sensors $\mathrm{A}(+$, blue $)$ and $\mathrm{B}(\mathrm{x}$, red $)$

preserve them. A first hint that the surface shear stress may have a significant influence on the structures can be seen in the similarity of the fields of low shear stress (Fig. 2) and low concentration of parcels (Fig. 9). To answer the question whether the clustering of parcels is caused by the spatial variability of aerodynamic entrainment due to the varying surface shear stress, or whether the airflow also concentrates the parcels into specific regions, we performed a simulation where we use the constant friction velocity instead of the surface shear stress shown in Sect. 5.1 to determine aerodynamic entrainment. This means that the friction velocity is now constant in space and time, directly influencing the particle entrainment (Eq. 8) and the airflow in the saltation layer through a change in roughness length (Eq. 5). The spatial distribution of the parcels in this simulation (Fig. 10) now significantly varies relative to the previous simulation (Fig. 9). The parcels are distributed approximately homogeneously over the domain. This indicates that, starting from a homogeneous parcel distribution in aerodynamic entrainment, the influence of the flow on the spatial distribution is limited in this simulation. The reason for the spatial variability of airborne snow mass and the fluctuations of local snow mass fluxes in this model experiment thus appears to be the spatial variability of aerodynamic entrainment caused by a varying surface shear stress. The shear-stress variability was already discussed by Doorschot et al. (2004) based on field observations and results of a one-dimensional saltation model. They confirmed the relevance of this parameter to obtaining a good estimate of the snow mass flux. It is likely that the spatial 


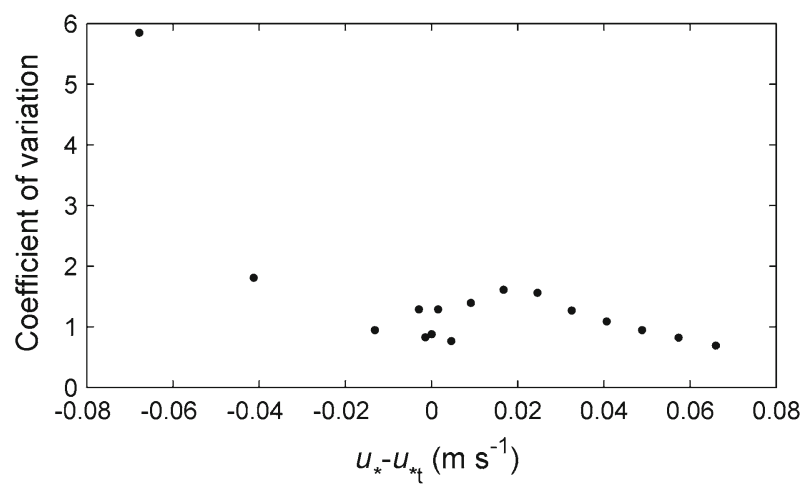

Fig. 11 Simulated mean coefficient of variation against $u_{*}-u_{* t}\left(\mathrm{~m} \mathrm{~s}^{-1}\right)$ as obtained from 50 virtual sensors placed close to the surface

variability of the surface shear stress indeed strongly influences the snow mass flux and the formation of streamers. We should, however, also note that the capability of the flow to form streamers, given a homogeneous entrainment, also depends on the particle size. Streamer formation solely due to convergence by eddies can be more likely for small particles. Finally, it also has to be considered that these results were obtained over flat terrain; in flows where topography has a distinct influence we may expect different results.

\subsection{Snow Mass-Flux Fluctuations for a Changing Threshold Friction Velocity}

The fluctuations of snow mass flux are influenced by turbulent structures, as shown in the previous sections. However, the relative influence of turbulent structures on the variations in snow mass flux can also depend on, for instance, the snow properties. A decisive factor is the friction velocity with respect to the threshold friction velocity. We here show that this model type is also capable of reproducing such typical behaviour. In an extra set of short simulations $(10 \mathrm{~s})$, we have chosen a fixed particle size and varied this between $0.55 \times 10^{-3} \mathrm{~m}$ and $1 \times 10^{-3}$ $\mathrm{m}$ to create differences between the threshold friction velocity and the friction velocity (also see Table 3). Note that the particle size also affects the particle relaxation time. We placed 50 virtual particle counters in the domain to obtain a reliable average of the snow mass flux and the coefficient of variation. These simulations confirmed that the model simulates snow mass fluxes increasing with a power of three with decreasing threshold friction velocity (not shown), as is known from observations (e.g. Nishimura and Hunt 2000; Clifton et al. 2006) and theoretical models (Doorschot and Lehning 2002). Moreover, we see a general decrease in the coefficient of variation with decreasing threshold friction velocity (Fig. 11), which agrees with reduced intermittency factors observed by Stout and Zobeck (1997). Close to the threshold snow transport is more intermittent, while increasing friction velocity enhances snow mass fluxes and causes a decrease of variability. This can also be demonstrated by the percentage of timesteps in which particles were present in the virtual sensor; this was only $15 \%$ near the threshold $\left(u_{*}-u_{* t}=0.005 \mathrm{~m} \mathrm{~s}^{-1}\right)$ and $87 \%$ for the simulation with smallest threshold friction velocity. While near the onset of saltation structures or eddies may have a relatively large effect on snow mass fluxes, this becomes smaller with increasing friction velocity. Moreover, far below the threshold, coefficients of variations are large as particles only occasionally pass the virtual sensor. 


\section{Discussion of Model Limitations}

Following the results discussed in previous sections, we would also like to discuss some model limitations. The results have shown that it is possible to simulate fluctuating saltation on short time scales and reliable vertical snow mass-flux profiles with this model set-up. They have, however, not shown that we can quantitatively and accurately describe small-scale snow transport. This was not the purpose of the study. This should, nonetheless, be possible when LES can reproduce the turbulence statistics seen over terrain such as the Weissfluhjoch Versuchsfeld, and the model can be calibrated and validated with high-frequency measurements of wind speed and snow transport.

Both a limitation and advantage is seen in the use of a wall function to describe the airflow close to the surface; this allows for snow transport simulations independent of LES and saves computational time. On the other hand, it does not allow for an explicit description of the interactions between the particles and the flow. Especially for small time scales, this can be relevant and a further topic of study is the implementation of this Lagrangian stochastic model directly in the LES. This is furthermore important because it may be able to limit the sensitivity of the model to parameters such as the initial velocity (see Sect. 5.2), since all the particles that are present will extract momentum from the flow and the feedback no longer has to be based on expected equilibrium number of particles. We therefore believe that this will also lead to improved quantitative results. This is in fact a large step as we are confronted with processes that take place close to the surface in a region smaller than the current model resolution. The promising results so far, showing that the drifting snow mass flux on short time scales may be described with this model set-up, are an encouragement for future efforts in this direction.

\section{Conclusions}

Drifting snow in complex terrain (e.g. Doorschot et al. 2004) as well as in wind tunnels (e.g. Guala et al. 2008) has been observed to be highly variable on short time scales. This was confirmed in the observations presented in this study. To gain understanding in these processes and to model drifting snow on small scales we need to consider the influence of turbulence. Our model study therefore investigated whether LES flow fields combined with a Lagrangian stochastic model are able to describe drifting snow on short time scales. The large sensitivity of the model to the initial velocity of particles, however, shows that the model should currently only be used for qualitative studies of drifting snow, as presented here. At the moment, the model is intended to provide a better process understanding of snow transport and, for example, to help design relevant experiments by determining necessary measurement resolutions rather than for reliable quantitative mass transport estimates.

Particularly different from other three-dimensional aeolian transport models based on LES is the usage of the fluctuating surface shear stress rather than the fluid friction velocity to obtain particle entrainment rates. Furthermore, previous model studies of snow or sand transport on small time scales have not addressed the spatial variability of the mass flux. The spatial variability, however, can have a large influence on the local time series of snow mass flux. While this is known from field observations, we showed that this model is able to reproduce structures of enhanced snow parcel numbers and subsequent variation in the snow mass-flux time series (streamers). A comparison of the modelled fluctuations in snow mass flux to observations from a field site and a wind tunnel showed that the fluctuations are realistic but stronger than in both observation types. This is related to the volume and time period 
over which (virtual) measurements are made and the length scales observed in drifting snow. Model results also showed that the friction velocity with respect to the threshold friction velocity affects snow mass-flux fluctuations, as has been observed by Stout and Zobeck (1997). Measurements regarding these fluctuations will be reported in the near future. The results foremost show the possibility of studying and describing intermittent drifting snow on short time scales with this type of model. Furthermore, the presented model results show that the surface shear stress has a large influence on the modelled spatial distribution of snow parcels. Structures in the snow-parcel distribution could not be retrieved if parcels were initially entrained homogeneously based on the friction velocity of the flow. The latter may also be due to the relatively large particle size and associated time scale of the particles in the current simulation. Moreover, we believe that implementing the Lagrangian snow transport model in the LES will give more reliable results for this particular aim.

Finally, we expect that the good representation of the flow field over complex terrain using the EPFL-LES (Diebold et al. 2013) will in future enable us to model drifting snow in such terrain and turbulent flows on short time scales. This is particularly useful since snow transport modelling in complex terrain based on mean flows shows limitations in describing the snow distribution in very steep terrain and on small scales. Furthermore, a coupling with a snow-cover model that describes the spatially varying snow-cover properties may reveal how local wind crusts or surface features influence snow transport.

Acknowledgments We thank Katherine Leonard and Roland Meister for their contribution to the drifting snow measurements at Weissfluhjoch Versuchsfeld. This project is funded by the Swiss National Science Foundation. We thank the reviewers for useful comments.

\section{References}

Albertson JD, Parlange MB (1999) Surface length scales and shear stress: implications for land-atmosphere interaction over complex terrain. Water Resour Res 35(7):2121-2132

Alfredsson PH, Johansson AV, Haritonidis JH, Eckelmann H (1988) The fluctuating wall-shear stress and the velocity field in the viscous sublayer. Phys Fluids 31(5):1026-1033

Anderson RS, Haff PK (1991) Wind modification and bed response during saltation of sand in air. Acta Mech Suppl 1:21-51

Araoka K, Maeno N (1981) Dynamical behaviour of snow particles in the saltation layer. In Proceedings of 3rd symposium on polar meteorology and glaciology. Memoirs of Nationa Institute of Polar Research, vol 19, Tokyo, pp 253-263

Baas ACW (2008) Challenges in aeolian geomorphology: investigating aeolian streamers. Geomorphology 93(1-2):3-16

Baas ACW, Sherman DJ (2005) Formation and behavior of aeolian streamers. J Geophys Res 110:F03011

Bagnold RA (1941) The physics of blown sand and desert dunes. Methuen, London, 265 pp

Bou-Zeid E, Meneveau C, Parlange M (2005) A scale-dependent Lagrangian dynamic model for large eddy simulation of complex turbulent flows. Phys Fluids 17(2):025105

Butterfield GR (1998) Transitional behaviour of saltation: wind tunnel observations of unsteady winds. J Arid Environ 39:377-394

Butterfield GR (1999) Application of thermal anemometry and high-frequency measurement of mass flux to aeolian sediment transport research. Geomorphol 29:31-58

Chester S, Meneveau C, Parlange MB (2007) Modeling turbulent flow over fractal trees with renormalized numerical simulation. J Comput Phys 225(1):427-448

Clifton A, Lehning M (2008) Improvement and validation of a snow saltation model using wind tunnel measurements. Earth Surf Process Landf 33:2156-2173

Clifton A, Rüedi J-D, Lehning M (2006) Snow saltation threshold measurements in a drifting snow wind tunnel. J Glaciol 39:585-596

Davidson PA (2004) Turbulence: an introduction for scientists and engineers. Oxford University Press, New York, $657 \mathrm{pp}$ 
Deardorff JW (1972) Numerical investigation of neutral and unstable planetary boundary layers. J Atmos Sci 29:91-115

Déry SJ, Yau MK (2001) Simulation of blowing snow in the canadian arctic using a double-moment model. Boundary-Layer Meteorol 99:297-316

Diebold M, Higgins C, Fang J, Bechmann A and Parlange M (2013) Flow over hills: a large-eddy simulation of the bolund case. Boundary-Layer Meteorol 148(1):177-194

Doorschot JJJ, Lehning M (2002) Equilibrium saltation: mass fluxes, aerodynamic entrainment, and dependence on grain properties. Boundary-Layer Meteorol 104(1):111-130

Doorschot JJJ, Lehning M, Vrouwe A (2004) Field measurements of snow-drift threshold and mass fluxes, and related model simulations. Boundary-Layer Meteorol 113(3):347-368

Ellis JT, Sherman DJ, Farrell EJ, Li B (2012) Temporal and spatial variability of aeolian sand transport: implications for field measurements. Aeolian Res 3(4):379-387

Gauer P (1999) Blowing and drifting snow in Alpine Terrain: a physically-based numerical model and related field measurements, Eidg. Institut für Schnee- und Lawinenforschung, Mitteilungen Nr 58, 128 pp

Germano M, Piomelli U, Moin P, Cabot WH (1991) A dynamic subgrid-scale eddy viscosity model. Phys Fluids A 3(7):1760-1765

Gordon M, Biswas S, Taylor PA, Hanesiak J, Albarran-Melzer M, Fargey S (2010) Measurements of drifting and blowing snow at Iqaluit, Nunavut. Canada during the STAR project. Atmos-Ocean 48(2):81-100

Groot Zwaaftink CD, Mott R, Lehning M (2013) Seasonal simulation of drifting snow sublimation in Alpine terrain. Water Resour Res 49:1581-1590

Guala M, Manes C, Clifton A, Lehning M (2008) On the saltation of fresh snow in a wind tunnel: profile characterization and single particle statistics. J Geophys Res 113:F03024

Hardalupas Y, Horender S (2001) Phase Doppler anemometer for measurements of deterministic spray unsteadiness. Part Part Syst Charact 18(4):205-215

Kok JF, Renno NO (2009) A comprehensive numerical model of steady state saltation (COMSALT). J Geophys Res 114:D17204

Lehning M, Löwe H, Ryser M, Raderschall N (2008) Inhomogeneous precipitation distribution and snow transport in steep terrain. Water Resour Res 44(7):W07404

Lenaerts JTM, van den Broeke MR (2012) Modeling drifting snow in Antarctica with a regional climate model: 2. Results. J Geophys Res 117:D05109

Lieberherr G (2010) Modeling snow drift in the turbulent boundary layer. MSc Thesis, EPFL, Lausanne, 36 pp

Lilly DK (1967) The representation of small-scale turbulence in numerical simulation experiments. In Proceedings of the IBM scientific computing symposium on environmental sciences. IBM Form No. 320-1951, White Plains, pp 195-209

Mann GW, Anderson PS, Mobbs SD (2000) Profile measurements of blowing snow at Halley Antarctica. J Geophys Res 105(D19):24491-24508

Moeng CH (1984) A large-eddy simulation model for the study of planetary boundary-layer turbulence. J Atmos Sci 41:2052-2062

Nemoto M, Nishimura K (2004) Numerical simulation of snow saltation and suspension in a turbulent boundary layer. J Geophys Res 109:D18206

Nield JM, Wiggs GFS (2011) The application of terrestrial laser scanning to aeolian saltation cloud measurement and its response to changing surface moisture. Earth Surf Process Landf 36(2):273-278

Nieuwstadt FTM, Brost RA (1986) The decay of convective turbulence. J Atmos Sci 43(6):532-546

Nishimura K, Hunt JCR (2000) Saltation and incipient suspension above a flat particle bed below a turbulent boundary layer. J Fluid Mech 417:77-102

Nishimura K, Nemoto M (2005) Blowing snow at Mizuho station Antarctica. Philos Trans Roy Soc 363(1832):1647-1662

Overney J (2006) Lagrangian stochastic modeling of heavy particle trajectories in atmospheric turbulence. MSc Thesis, EPFL, Lausanne, 55 pp

Pomeroy JW, Marsh P, Gray DM (1997) Application of a distributed blowing snow model to the arctic. Hydrol Proc 11(11):1451-1464

Porté-Agel F, Meneveau C, Parlange MB (2000) A scale-dependent dynamic model for large-eddy simulation: application to a neutral atmospheric boundary layer. J Fluid Mech 415:261-284

Raupach MR (1991) Saltation layers, vegetation canopies and roughness lengths. Acta Mech Suppl 1:83-96

Rice MA, Willetts BB, McEwan IK (1995) An experimental study of multiple grain-size ejecta produced by collisions of saltating grains with a flat bed. Sedimentol 42(4):695-706

Sato T, Higashiura M (1997) Characteristics of blowing snow fluctuation. In: Izumi M et al (eds) Snow engineering: recent advances. Balkema, Rotterdam, $650 \mathrm{pp}$ 
Sato T, Uematsu T, Kaneda Y (1997) Application of random walk model to blowing snow. In: Izumi M et al (eds) Snow engineering: recent advances. Balkema, Rotterdam, $650 \mathrm{pp}$

Schmidt RA (1982) Vertical profiles of wind speed, snow concentration, and humidity in blowing snow. Boundary-Layer Meteorol 23:223-246

Schneiderbauer S, Prokop A (2011) The atmospheric snow-transport model: SnowDrift3D. J Glaciol 57(203):526-542

Shao Y, Li A (1999) Numerical modelling of saltation in the atmospheric surface layer. Boundary-Layer Meteorol 91:199-225

Smagorinsky J (1963) General circulation experiments with the primitive equations: I. The basic experiment. Mon Weather Rev 91(3):99-164

Soldati A (2005) Particles turbulence interactions in boundary layers. Z Angew Math Mech 85(10):683-699

Sterk G, Jacobs AFG, Van Boxel JH (1998) The effect of turbulent flow structures on saltation sand transport in the atmospheric boundary layer. Earth Surface Process Landf 23:877-887

Stout JE, Zobeck TM (1997) Intermittent saltation. Sedimentology 44:959-970

Stull RB (1988) An introduction to boundary layer meteorology. Kluwer Academic Publishers, Dordrecht, $666 \mathrm{pp}$

Sturm M, Stuefer S (2013) Wind-blown flux rates derived from drifts at arctic snow fences. J Glaciol 59(213):21-34

Sugiura K, Maeno N (2000) Wind-tunnel measurements of restitution coefficients and ejection number of snow particles in drifting snow: Determination of splash functions. Boundary-Layer Meteorol 95(1):123-143

Sugiura K, Nishimura K, Maeno N, Kimura T (1998) Measurements of snow mass flux and transport rate at different particle diameters in drifting snow. Cold Reg Sci Technol 27(2):83-89

Sundsbø PA, Hansen EWM (1997) Modelling and numerical simulation of snow drift around snow fences. In: Izumi $\mathrm{M}$ et al (eds) Snow engineering: recent advances. Balkema, Rotterdam

Thomson DJ (1987) Criteria for the selection of stochastic models of particle trajectories in turbulent flows. J Fluid Mech 180:529-556

Tong D, Huang N (2012) Numerical simulation of saltating particles in atmospheric boundary layer over flat bed and sand ripples. J Geophys Res 117:D16205

Vinkovic I (2005) Dispersion et mélange turbulents de particules solides et de gouttelettes par une simulation des grandes échelles et une modélisation stochastique lagrangienne. $\mathrm{PhD}$ thesis, Ecole centrale de Lyon

Vinkovic I, Aguirre C, Ayrault M, Simoëns S (2006) Large-eddy simulation of the dispersion of solid particles in a turbulent boundary layer. Boundary-Layer Meteorol 121(2):283-311

Vionnet V, Guyomarc'h G, Martin E, Durand Y, Bellot H, Bel C, Puglièse P (2013) Occurrence of blowing snow events at an alpine site over a 10-year period: observations and modelling. Adv Water Resour 55:53-63

Weil JC, Sullivan PP, Moeng CH (2004) The use of large-eddy simulations in Lagrangian particle dispersion models. J Atmos Sci 61:2877-2887

Wilson JD (2000) Trajectory models for heavy particle in atmospheric turbulence: comparison with observations. J Appl Meteorol 39:1894-1912

Winstral A, Marks D (2002) Simulating wind fields and snow redistribution using terrain-based parameters to model snow accumulation and melt over a semi-arid mountain catchment. Hydrol Proc 16(18):3585-3603 